DOI: http://dx.doi.org/10.33846/hn50503

http://heanoti.com/index.php/hn

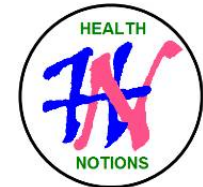

RESEARCH ARTICLE

URL of this article: http://heanoti.com/index.php/hn/article/view/hn50503

\title{
Effectiveness of Leininger's Transcultural-based GATHER Counseling Model on
} Exclusive Breastfeeding

\author{
I Gusti Ayu Karnasih ${ }^{1(\mathrm{CA})}$ \\ ${ }^{1(\mathrm{CA})}$ Department of Midwifery, Poltekkes Kemenkes Malang, Indonesia; i_gusti@poltekkes-malang.ac.id
} (Corresponding Author)

\begin{abstract}
Objective: to analyze the effectiveness of Leininger's Transcultural-based GATHER (Greet, Ask, Tell, Help, Explain, and Return/refer) Counseling Model for exclusive breastfeeding. Methods: The experimental research was conducted with the post-test only control group design. The sample size of control group and treatment group were 38 people. The sampling technique is a simple random sampling technique. The treatment group were third stage III pregnant women with a gestational age of 36-37 weeks and at the second day postpartum. Data were collected using questionnaires and observations of 76 breastfeeding mothers in Jember Regency, then analyzed using Mann Whitney-U test. Results: The results showed that postpartum mothers who were given Leininger's Transcultural-based GATHER Counseling Model showed a higher percentage of exclusive breastfeeding $(81.1 \%)$ than postpartum mothers who were not given counseling $(21.6 \%)$. The results of hypothesis testing showed p-value of 0.000 , meaning that the hypothesis was accepted so that it could be said that exclusive breastfeeding for mothers who were given counseling was higher than those who were not given Leininger's Transcultural-based GATHER Counseling Model and it was effective in increasing milk production. Conclusion: Leininger's Transcultural-based GATHER Counseling Model is effective in increasing exclusive breastfeeding, this model facilitates understanding and management of the factors that cause problems, breastfeeding.
\end{abstract}

Keywords: exclusive breastfeeding; GATHER counseling model; Leininger's transcultural model

\section{INTRODUCTION}

\section{Background}

Exclusive breastfeeding is defined as giving breastfeeding as nutrition for the baby without any additional food, including water. Exclusive breastfeeding is a government program. The government targets $80 \%$ of babies to receive exclusive breastfeeding. Besides that, exclusive breastfeeding is right for every baby in the first six months old, because the baby's digestion is suitable only for breast milk. Exclusive breastfeeding can improve infant health, growth and development. Babies who are exclusively breastfed have good intellectual, emotional and spiritual intelligence. However, not all babies get their rights properly.

Worldwide recorded that exclusive breastfeeding was still low. Babies in the world are not more than $42 \%$ exclusively breastfed in the first month of life and $41 \%$ are exclusively breastfed for 6 months (1), According to Riskesdas 2018, exclusive breastfeeding in Indonesia is less than $40 \%{ }^{(2)}$. East Java exclusive breastfeeding by $50 \%$. In Jember, $50 \%$ of exclusive breastfeeding was based on data from Riskesdas East Java $2018^{(3)}$. Postpartum mothers do not provide exclusive breastfeeding due to many factors, including internal and external factors. External factors are factors that have a major role in the failure of exclusive breastfeeding. These factors are related to the socio-culture adopted by the family and society. Socio-cultural problems cannot be overcome by increasing the knowledge of postpartum mothers and families through GATHER counseling alone, but it requires a culture-based approach. The approach that must be taken in overcoming socio-cultural problems is counseling with a socio-cultural approach in accordance with Leininger's transcultural concept. Babies who are not exclusively breastfed have an impact on infant and maternal morbidity and mortality. Babies are prone to diarrhea. Non-exclusive breastfeeding has an impact on high morbidity and has an indirect impact $\mathbf{1 5 6}$ | Publisher : Humanistic Network for Science and Technology 
on infant mortality. Babies who are not exclusively breastfed get sick more easily. Diarrhea is the biggest case suffered by infants as a result of non-exclusive breastfeeding ${ }^{(4)}$. Besides, the growth and development of babies can experience delays due to inadequate nutrition received ${ }^{(5)}$. Of course, this has a negative effect on the quality of future Indonesia's human resources.

Solutions to overcome the problem of breastfeeding have been carried out with various approaches. These solutions have not been able to solve the causes of breastfeeding problems. The treatment that is carried out tends to be fragmented in only one cause. An approach is needed that can address all causes of breastfeeding problems, especially those related to the socio-cultural community. Social and cultural factors are the root causes of the failure of exclusive breastfeeding. Leininger's Transcultural-based GATHER Counseling Model is one solution that can be applied to facilitate mothers to be able to make clear and mature decisions in breastfeeding their babies. Leininger's Transcultural-based GATHER Counseling Model is a counseling process with stages starting with establishing a rapport, followed by an assessment, which is combined with the Leinnanger transcultural component at each stage. Leininger's components include technology, religion and philosophy of life, social and family ties, cultural values, and lifestyle, regulations and policies, economy, education.

\section{Purpose}

The study objectives were to analyze the effectiveness of the Leininger's Transcultural-based GATHER Counseling Model in improving mother of giving exclusive breastfeeding.

\section{METHODS}

The design of this research was an experimental study, the effectiveness of the application of the Leininger's Transcultural-based GATHER Counseling Model at the time of antepartum to exclusive breastfeeding for postpartum mothers who were not given Leininger's Transcultural-based GATHER Counseling Model. The population in this study was the third stage, pregnant women, with estimated delivery in Maret to November 2019. The sample size was 76 third stage, pregnant women. The simple random sampling technique was applied to determine the treatment and control group.

The treatment group was given to third stage III pregnant women with a gestational age of 36-37 weeks and at the second day postpartum. The control group was getting treatment like the counseling still of care from the place of care. Data collection from the treatment and control groups was carried out from birth to 6 months old. The category of exclusive breastfeeding was that babies get colostrum, babies drink only breast milk every 2 or 3 hours and don't get any other food or drink including water. The collected data were analyzed descriptively in the form of frequency and percentage. Hypothesis testing at the $95 \%$ confidence interval was used to test the effectiveness of the Leininger's Transcultural-based GATHER Counseling Model for exclusive breastfeeding.

\section{RESULTS}

Table 1 shows the distribution of breastfeeding of postpartum mothers who were given the Leininger's Transcultural-based GATHER Counseling Model and those who were not given.

Table 1. Distribution of breastfeeding for postpartum mothers who were given the Leininger's Transculturalbased GATHER Counseling Model and those who were not given

\begin{tabular}{ccccc}
\hline \multirow{2}{*}{ Breastfeeding } & \multicolumn{2}{c}{ Routine counseling } & \multicolumn{2}{c}{$\begin{array}{c}\text { Leininger's Transcultural-based } \\
\text { GATHER Counseling Model }\end{array}$} \\
\cline { 2 - 5 } & Frequency & Percentage & Frequency & Percentage \\
\hline Exclusive breastfeeding & 8 & 21.1 & 31 & 81.6 \\
\hline Non-exclusive breastfeeding & 30 & 78.9 & 7 & 18.4 \\
\hline Total & 38 & 100 & 38 & 100 \\
\hline
\end{tabular}

Table 2 shows the effectiveness of GATHER counseling model based on Leinenger's Transcultural Gather-based Counseling Model on exclusive breastfeeding. The results of hypothesis testing show that the pvalue was 0.000 , so it was interpreted that there was a difference in the success of breastfeeding between group who were given Leininger's Transcultural-based GATHER Counseling Model and group who were given routine counseling. 
Table 2. The effectiveness of the Leininger's Transcultural-based GATHER Counseling Model on exclusive breastfeeding

\begin{tabular}{ccccc}
\hline & & $\mathrm{n}$ & Mean rank & $\mathrm{p}$-value \\
\hline \multirow{2}{*}{$\begin{array}{c}\text { Exclusive } \\
\text { breastfeeding }\end{array}$} & Leininger's Transcultural-based GATHER Counseling Model & 38 & 50 & 0.000 \\
\cline { 2 - 5 } & Routine counseling & 38 & 27 & \\
\hline & Total & 76 & & \\
\hline
\end{tabular}

\section{DISCUSSION}

The results showed that the Leininger's Transcultural-based GATHER Counseling Model was effective in increasing exclusive breastfeeding. Postpartum mothers who were given the Leininger's Transcultural-based GATHER Counseling Model could decide to breastfeed their babies exclusively because they had good knowledge, there was support from family, the mother knew the correct culture and cultures that should not be followed. A culture shaped the individual's lifestyle according to the culture that had been studied since they were children ${ }^{(1)}$. A person's lifestyle affects one's perception of a concept.

The decision to breastfeed exclusively for mothers who received the Leininger's Transcultural-based GATHER Counseling Model, in each stage of GATHER counseling, 7 Leininger's Transcultural components were applied, including technological factors, religious and philosophical factors, social and attachment factors, family, cultural values, and lifestyle factors, political and legal factors, economic factors, educational factors. These multi factors were the causes of the failure to exclusively breastfeed ${ }^{(2),(3)}$. Cultural beliefs and positive social were also influenced exclusive breastfeeding to sustain the child's health and intellectual development.

The multidimensional approach employed in the Leininger's Transcultural-based GATHER Counseling Model could overcome all breastfeeding problems. The interactions among women, their friends and families, and the broader historical social, political, economic, institutional, and community contexts shaped the knowledge, behavior, and attitudes of individuals as seen in the social-ecological perspective. Therefore effective breastfeeding interventions had to reflects all of these aspects ${ }^{(4)}$. It could be seen from the research that the results showed that only $21.1 \%$ of mothers gave breastfeeding exclusively to their babies, while mothers who received the Leininger's Transcultural-based GATHER Counseling Model were 81.6\%. One of the techniques used was cultural modification with the application of Leinenger's transcultural theory to increase breast milk production ${ }^{(5)}$.

The initial stage of GATHER Counseling was to establish a good report card between the counselor and the counselee. Report cards were established faster in postpartum mothers who were given the Leininger's Transcultural-based GATHER Counseling Model compared to those who were not. A culture-based counseling approach had an impact on the psychology of postpartum mothers. Postpartum mothers feel valued and accepted as was in accordance with the culture adopted. One example was the use of language in the counseling process. The counseling process using postpartum mother tongue could facilitate the mother's grasp of the content of the counseling and the mother was more open and felt the counselor can understand her condition. It was not uncommon for postpartum mothers to ask with a happy expression, "Do you speak Madurese?" After that, they began to be more open in expressing their problems and perceptions about breastfeeding. Not only the use of language but the way of greeting in the early stages of counseling also affects the continuity of counseling. The formation of a good report card affected the sustainability of the counseling process.

The next stage was the asking stage, providing information and helping made choices. The questions asked by the counselor affected the data obtained by the counselor. Questions that only examine superficial matters would not get data according to the real conditions of postpartum mothers regarding exclusive breastfeeding. the Leininger's Transcultural-based GATHER Counseling Model was carried out in a detailed and specific manner and includes 7 Leininger's Transcultural components. The habits and behavior of the community were influenced by the culture adopted by the community, so that community culture was a factor that must be studied related to exclusive breastfeeding. The problem of breastfeeding was mostly caused by factors of community habits and community behavior ${ }^{(6)}$. The main problem of failure to exclusively breastfeed was the failure to breastfeed in the early postpartum period, namely on the first to the third day postpartum. This happened because physiologically the production of breast milk, in this case, colostrum, was in accordance with the baby's needs. At this time, the need for each breastfeeding baby was only about 5-10 cc according to the size of the new baby's stomach as big as a small marble. But mothers and families thought that babies should drink a lot, and people had a habit of giving Supplementary foods. Therefore, actions to increase mother's knowledge and teach how to increase milk production needed to be done. Education about breastfeeding was very effective at increasing exclusive breastfeeding ${ }^{(7)}$.

There were community cultures that support exclusive breastfeeding and some inhibit exclusive breastfeeding. The real form of community culture began with the perception of breastfeeding. There were positive and negative perceptions of society about breastfeeding. The breastfeeding process and exclusive r. 158 | Publisher: Humanistic Network for Science and Technology 
breastfeeding could be interfered by negative perceptions. The perception of milk was watery and had a bad odor (8), breastfeeding could affect the appearance of the mother, complaints of stomach pain that had to be treated, there was a fear of the evil eye when breastfeeding in public, breast milk might become unclean, and there was a need for pauses in breastfeeding after the child burps. In this study, most of the postpartum mothers came from a Madurese background. The Madurese had a positive and negative culture towards breastfeeding. Both cultures had to be studied to obtain valid data on the causes of breastfeeding failure and could be used in providing interventions according to the causes complained of by mothers and families. Positive cultures were used by counselors to strengthen the understanding of postpartum mothers about breastfeeding and sources of praise for postpartum mothers to keep it applied. The negative culture towards breastfeeding was negotiated with the mother and family and explained to the mother and family the negative impact if this culture was continued. The position and attachment of breastfeeding were heavily influenced by culture passed down from generation to generation and were difficult to change. One of the habits of postpartum mothers was the position of breastfeeding by placing the baby on a pillow that the mother was holding. This position was very uncomfortable for the baby. Mothers had been taught how to carry the baby, but still carried the baby as the habit that had been applied in their family. After the study, it was found that the method of holding the baby was to prevent the baby's head from being symmetrical. The perception of a baby's head changes shape because it was placed on the hard elbows thriving in society. With the Leininger's Transcultural-based GATHER Counseling Model it could be assessed well. Based on this perception, at the time of telling/providing information, the mother and family have explained the bone structure of the baby's head, and shown the reality that it was impossible for the head to change shape. Besides, it also explains the process of breastfeeding that alternates between the left and right breasts, allowing the baby's head to get the same emphasis on both sides so that changes in the shape of the head will not occur.

Cultural values and lifestyle factors were the points studied and in providing information and explaining so that postpartum mothers could make the best decisions for their babies, namely giving breast milk only until the age of 6 months. Cultural values that support breastfeeding, especially increasing milk production, were the habits of the Madurese people to consume vegetables, especially green vegetables/ foreskin. Green vegetables contain enough vitamins that can improve the health status of the mother. A physically healthy mother can produce enough milk. Vegetables that were believed by the Madurese to increase breast milk production were katu leaves and beletah leaves. Beletah leaves were leaves from creeping plants that were believed to increase milk production. Based on the recognition of several postpartum mothers $(70 \%)$ stated that breast milk production increased after consuming boiled Gymnema sylvestre leaves. The negative habit in consuming vegetables was the way of processing vegetables. The Madurese had a habit of cooking vegetables until they were too ripe so that the content of vitamins and other nutrients was damaged. Based on this study, the counselor provided information on how to cook vegetables with family-filled communication and jokes according to the culture of the community so that they did not feel offended and blamed. After they realized for themselves that their behavior was wrong, they decided to cook the vegetables properly. The Madurese community also had the habit of performing breast scrapings to overcome breast milk dams, this action was an action that could make the mother more in pain and the possibility of infection/mastitis. In the Leininger's Transcultural-based GATHER Counseling Model, the community's habits were carried out a deeper study, whereas in the previous counseling it was not carried out, it was only considered as a habit. The results of a more detailed assessment on prevention and overcoming breast milk dams can be used as a basis for providing information so that postpartum mothers do not experience breastfeeding dams and exclusive breastfeeding is carried out.

In the Madurese tribe, there was a culture: parents accompany postpartum mothers until the baby was 40 days old. Treatment during this time was up to the parents' decision. Parents require postpartum mothers to rest to restore their energy so that more baby care was done by parents. Parents gave baby food according to the experience that had been passed down from generation to generation. In counseling without being based on the the Leininger's Transcultural, counseling was only given to postpartum mothers so that only postpartum mothers understand exclusive breastfeeding, while parents as decision-makers were not involved. This condition caused families to tend to provide negative support to postpartum mothers ${ }^{(9)}$. The form of non-probreastfeeding support that was often done by mothers was to encourage postpartum mothers to give formula milk on days 1 and 2 because the production of milk was less according to the family ${ }^{(10)}$. Another mistaken belief was that babies gained weight rapidly when fed on infant formulas ${ }^{(9)}$. The family does not understand that colostrum production was in accordance with the needs of the baby and the size of the baby's stomach with a capacity of $\pm 5 \mathrm{cc}$. Newborns in the first 24 hours of life need only $1.5+/-1.1 \mathrm{~g}$ of milk ${ }^{(11)}$. Newborns had brown fat as a supply of nutrients. Babies with brown fat could maintain their body temperature in normal conditions so that on the first day the baby did not need excess calories from outside the body ${ }^{(12)}$. Poor adhesion was one of the main causes of mothers not exclusively breastfeeding ${ }^{(13)}$.

Postpartum mothers synthesize perceptions based on previous experiences, namely the mother's fear of a repetition of the problems experienced. Mothers were afraid of experiencing recurrent mastitis while breastfeeding their babies. Researchers handled the mother's perception by explaining the causes of mastitis and the prevention that had to be done so that mastitis did not occur was to carry out regular breast care and 
breastfeeding the baby every 2-3 hours and expressing the breast if the milk was still left on the breast after the baby was sufficiently breastfed. Even though the explanation had been given about this, the mother still felt anxious and afraid that she would not be able to exclusively breastfeed her second baby. With the the Leininger's Transcultural-based GATHER Counseling Model, the counselor used technology, namely by doing hypnobreastfeeding to awaken the subconscious mind that the mother was able to breastfeed after the baby was born smoothly and the whole process runs smoothly. This positive goal was suggested to postpartum mothers so that in time the mother could breastfeed properly and smoothly. The subconscious mind that had positive goals affects better results ${ }^{(14)}$. Mothers who did hypnobreasthfeeding can increase milk production ${ }^{(15)}$.

The assessment of technological factors was carried out well in the Leininger's Transcultural-based GATHER Counseling Model. Understanding mothers and families about technological factors that influenced the success of breastfeeding needs to be done to overcome possible problems with breastfeeding. Constraints in the breastfeeding process were one of the themes found in exclusive breastfeeding ${ }^{(16)}$. Technology with the process of breastfeeding and increasing the secretion of hormones that affected milk production and excretion had to be understood by mothers and their families so that breastfeeding problems could be prevented and overcome. Correct breastfeeding techniques including breastfeeding position and attachment between the baby's mouth and the mother's breast were basic technologies that postpartum mothers had to master, obtained through the counseling process ${ }^{(17)}$. The lack of understanding of mothers and families about breast care, oxytocin massage, endorphin massage, guinea pig technique for expressing breast milk, and how to store breast milk needs attention and management. Oxytocin massage is part of the technology that has an impact on increasing oxytocin secretion ${ }^{(18)}$ and increasing breast milk production ${ }^{(19)}$.

Expression of breastmilk after breastfeeding could increase milk production. This was in accordance with the concept of demand and production, when the breast was empty it stimulates the anterior pituitary to secrete prolactin so that breast milk was produced. If the milk was not excreted, it would accumulate in the lobes and cause milk damages. Breast milk dam was an obstacle for mothers to exclusively breastfeed ${ }^{(20)}$. Even if there was no dam, the remaining milk in the breast could stimulate the secretion of inhibitors so that milk production was inhibited or produced in limited quantities. This condition caused the levels of prolactin and oxytocin to be not maintained. Postpartum mothers expressing breast milk after being given counseling had an impact on milk production and breastfeeding sustainability.

The study of religion and how the perception of mothers and families about the female body and the role of mothers was carried out in the application of this counseling model. Religion and the philosophy of life of mothers and families have a strong influence on mother behavior. The counselor, in the information stage, helped the mother make the choice that the mother should breastfeed her baby using the postpartum mother's religion and philosophy of life to strengthen her desire to exclusively breastfeed her baby. The counselor provides reaffirmation about the role of the mother and the greatness of God to create breasts that develop at the time of puberty and during pregnancy only occurs in the woman's body and the belief that all women are given the opportunity and responsibility to breastfeed their babies in their role as a mother. The approach of religion and philosophy of life had a faster impact on the acceptance of the concepts conveyed and applied in the form of behavior, in this case, exclusive breastfeeding ${ }^{(21)}$.

Social and familial factors that need to be studied by nurses in relation to exclusive giving were decisionmakers in the family ${ }^{(2)(2)}$. Cultural beliefs and positive social were also identified including the relation of breast milk with child health and intellectual development ${ }^{(23)}$. Assessment of decision-makers in the family was important because people who made decisions related to exclusive breastfeeding must have a good knowledge of exclusive breastfeeding. A person could make good decisions if he understands what to decide. Family members who made decisions in the care of postpartum mothers in Madurese and Javanese culture were parents, especially female parents. Most of the parents of postpartum mothers did not understand exclusive breastfeeding, prevention, and management of breastfeeding problems. This had an impact on the support they provide tends to contradict the concept of exclusive breastfeeding. Family support for Madurese mothers had an impact on the failure to provide exclusive breastfeeding (24). In the Leininger's Transcultural-based GATHER Counseling Model, counseling was also carried out to family members who play a role in making decisions. Providing counseling to decision-makers had an impact on positive support to postpartum mothers so that the mother's decision to exclusively breastfeed the baby. Previous counseling only focused on mothers which could not be implemented because of the lack of knowledge of the family who played a role in making decisions. Good family support and family knowledge have a positive effect on exclusive breastfeeding ${ }^{(25)}$.

The regulations and policies relating to exclusive breastfeeding were agreed upon globally by WHO and UNICEF. Both institutions launched the Baby-friendly Hospital Initiative / BFHI to improve health facilities around the world to further support breastfeeding ${ }^{(26)}$. The initiative posted Ten Steps of Successful Breastfeeding to promote optimal clinical care for new mothers and their babies. There was meaningful evidence that adopting the Ten Steps undoubtedly increases the rates of breastfeeding. In fact, not all health workers and health services apply it, and a lack of ad- equate health service support involving not only biological but also social and cultural factors. The disconnection between the scientific discourse and families' every- day cultural practices (27). 
Postpartum mothers also did not understand the existing regulations and policies so that they cannot demand services according to the established regulations. The study of postpartum mothers' understanding of regulations and policies related to the Leininger's Transcultural-based GATHER Counseling Model could be used as a basis for providing information according to maternal problems. One example of a policy that was very important for mothers to know was the Early Initiation of Breastfeeding EIBF and rooming-in practice. Not all health services apply EIBF and rooming-in practice in their delivery services ${ }^{(28),(29)}$. Nationally, the standard of normal childbirth care had been set, which includes the steps to do EIBF, but not all mothers giving birth have EIBF. Because EIBF could increase milk production and duration of exclusive breastfeeding ${ }^{(30)}$. Most mothers did not understand EIBF and did not get formal information about EIBF. The level of education affected EIBF ${ }^{(31)}$. By understanding the importance of EIBF for the continuation of breastfeeding, mothers who gave birth can ask the staff to do EIBF or before determining the place of delivery.

Assessment of the economy including family income and priority use of family income associated with breastfeeding has not been well studied in mothers who were not given the Leininger's Transcultural-based GATHER Counseling Model. Family income affects the fulfillment of family needs. The economic condition of the family influences the mother's decision to exclusively breastfeed her baby ${ }^{(2)}$. Mothers who do not receive the Leininger's Transcultural-based GATHER Counseling Model are forced to buy affordable formula milk with their finances to meet the nutritional needs of their babies and some mothers claim to provide water and solid foods such as banana scraps, young coconut, or rice that are mashed or crushed by their mothers. before being given to the baby. While mothers received counseling using the Leininger's Transcultural-based GATHER Counseling Model in third stage pregnancy, they had intended to breastfeed their babies and they stated that instead of buying formula milk, I would rather just breastfeed, the money could be used for other purposes. The results of the study on the economic status of the family can be used as material to provide information (tell) that breastfeeding is economically very supportive of the family economy, which means that the family does not need to spend extra money to buy formula milk if the mother is breastfeeding her baby. Besides that, the benefits also have an impact on the family's financial allocation so that babies who are given breast milk do not get sick easily. Meanwhile, babies who are given breast milk get sick very easily, especially infectious diseases. This happens because newborns are very susceptible to infection because their immune systems are not yet fully developed. The composition of colostrum which is rich in immunoglobulin is the physiological mechanism of the baby's body as long as the infant's immunological system is not fully formed. This can be seen from the results of a study of infants who were not exclusively breastfed stating that their babies were often sick with colds and diarrhea, on the other hand, mothers who gave exclusive breastfeeding had their babies rarely got $\operatorname{sick}^{(32)}$.

\section{CONCLUSION}

The Leininger's Transcultural-based GATHER Counseling Model could enhance exclusive breastfeeding. With the counseling model, starting with a report card to the referral process based on the culture of postpartum mothers and families. The study based on Leininger's transcultural concept would get complete data about the aspects that affect postpartum mothers, starting from perceptions about technology, religion and life philosophy, social and family ties to cultural values and lifestyle, economics, education related to breastfeeding, this would establish a relationship well and all breastfeeding problems related to culture could be assessed and information provided to postpartum mothers according to the problem, and in providing information with counseling all maternal problems could be collected through the question and answer stage. The problems that had been raised can be used as materials to provide information to patients. Mother and family's understanding of breastfeeding had a positive impact on breastfeeding behavior.

the Leininger's Transcultural-based GATHER Counseling Model was effective in increasing breast milk production. The existence of a clear understanding of religion, beliefs, values in society, technology can increase milk production and the sustainability of mothers in breastfeeding their babies.

\section{REFERENCES}

1. Albert I, Trommsdorff G. The Role of Culture in Social Development Over the Lifespan: An Interpersonal Relations Approach. Online Readings Psychol Cult. 2014;6(2):1-30.

2. Muchacha M, Mtetwa E. Social and Economic Barriers to Exclusive Breast Feeding In Rural Zimbabwe. Int J MCH AIDS. 2015;3(1):16-21.

3. Habibi M, Zahra F, Aguenaou H, Doukkali L. International Journal of Pediatrics and The impact of maternal socio-demographic characteristics on breastfeeding knowledge and practices: An experience from. Int J Pediatr Adolesc Med. 2018;5(2):39-48.

4. Thomas J. Barriers to exclusive breastfeeding among mothers during the first four weeks postpartum. 2016;1-108.

5. Awatiful Azza CS. The Application of Transcultural Nursing Model in Perspective of Madura Culture Improve Breastfeeding Mother's Behavior in Jember. 2017. 
6. Daglas M, Antoniou E. Earth science journal ®. 2012;6(2):353-61.

7. Froozani MD, Permehzadeh K, Dorosty Motlagh AR, Golestan B. Effect of breastfeeding education on the feeding pattern and health of infants in their first 4 months in the Islamic Republic of Iran. Bull World Health Organ. 1999;77(5):381-5.

8. Osman H, Zein L El, Wick L. Cultural beliefs that may discourage breastfeeding among Lebanese women : a qualitative analysis. 2009;6:1-6.

9. Nsiah-Asamoah C, Teye D, Doku SA. Mothers' and Grandmothers' misconceptions and socio-cultural factors as barriers to exclusive breastfeeding: A qualitative study involving Health Workers in two rural districts of Ghana. PLoS One. 2020.

10. Hawley NL, Rosen RK, Strait EA, Raffucci G, Holmdahl I, Freeman JR, et al. Mothers' attitudes and beliefs about infant feeding highlight barriers to exclusive breastfeeding in American Samoa. Women Birth J Aust Coll midwives. 2015;28(3):e80-e86.

11. Santoro W. Colostrum Ingested during the First Day of Life by Exclusively Breastfed Healthy Newborn Infants. J Paediatr. 2009.

12. Leitner BP, Huang S, Brychta RJ, Duckworth CJ, Baskin AS, McGehee S, et al. Mapping of human brown adipose tissue in lean and obese young men. Proc Natl Acad Sci U S A. 2017;114(32):8649-54.

13. Thomas JV. Barriers to Exclusive Breastfeeding Among Mothers During the First Four Weeks Postpartum. Walden Diss Dr. Sch. 2016.

14. Tanja-Bipp AK. Subconscious performance goals: Investigating the moderating effect of negative goaldiscrepancy Feedback. Hum Perform. 2018;

15. Pratiwi YS, Handayani SLMA. Pengaruh Hypnobreastfeeding Terhadap Produksi ASI. J Kesehat Qamarul Huda. 2018;1(5):49-56.

16. Reinsma K. Incorporating cultural beliefs in promoting exclusive breastfeeding. Afr J Midwifery Womens Heal. 2012;

17. Tiruye G, Firehiwot Mesfin BG, KS. Factors Affecting Exclusive Breastfeeding. 2018;6(3):260-71.

18. Sulaeman ES, Yunita FA. The Effect of Oxytocin Massage on The Postpartum Mother on Breastmilk Production in Surakarta Indonesia. 2016.

19. Rahayuningsih T, Mudigdo ABM. Effect of Breast Care and Oxytocin Massage on Breast Milk Production: A study in Sukoharjo Provincial Hospita. JMCH. 2016.

20. Kavle JA, Picolo M, Buccini G, Barros I, Chloe H, Dillaway RP-E. Strengthening counseling on barriers to exclusive breastfeeding through use of job aids in Nampula, Mozambique. PLoS One. 2019;

21. Faradilah A, Akbar. Religeous Knowledge And B reastfeeding Mothers Status. 2017;1(1):101-4.

22. Wanjohi M, Griffiths P, Wekesah F, Muriuki P, Muhia N, Musoke RN, Fouts HN, NJM, EWK-M. Sociocultural factors influencing breastfeeding practices in two slums in Nairobi, Kenya. Int Breastfeed J. 2017.

23. Paez KA, Allen JK, Beach MC. Relationship, Physician Cultural Competence and Patient Ratings of the Patient-Physician. Springer link. 2009.

24. Widyastutik O, Trisnawati E. Determinan Kegagalan Asi Eksklusif Pada Komunitas Madura. Ikesma. 2018;14(2):121.

25. Ratnasari D, Paramashanti BA, Hadi H, Yugistyowati A, Astiti D, Nurhayati E. Family support and exclusive breastfeeding among Yogyakarta mothers in employment. Asia Pac J Clin Nutr. 2017;26(March):S31-5.

26. WHO. Implementation Guidance 2018. 2018.

27. Albuquerque CDM De, Martins MC. Práticas culturais sobre aleitamento em um Programa de Saúde da Família. 2009;43(4):895-901.

28. Babu RA, Keepanasseril A, Kanimozhi K. Practice of Early Initiation of Breastfeeding among Postnatal Mothers in a Tertiary Hospital in South India. 2018;18-20.

29. Küçüközkan T. Early initiation and exclusive breastfeeding: Factors influencing the attitudes of mothers who gave birth in a baby-friendly hospital Emzirmeye başlama ve sadece anne sütüyle besleme : Bebek. $2017 ; 1-9$.

30. Walsh SM, Cordes L, McCreary L. Effects of Early Initiation of Breastfeeding on Exclusive Breastfeeding Practices of Mothers in Rural Hait. J Pediatr Helth Care. 2019.

31. Acharya P, Khanal V. The effect of mother's educational status on early initiation of breastfeeding : further analysis of three consecutive Nepal Demographic and Health Surveys. BMC Public Health. 2015.

32. Duijts L, Jaddoe VWV, Hofman A, Moll H. Prolonged and exclusive breastfeeding reduces the risk of infectious diseases in infancy. Pediatrics. 2010;126(1):e18-25. 